\title{
ERGONOMIC EVALUATION OF SUBJECTS INVOLVED IN ORANGE (Citrus sinensis) HANDLING OPERATIONS IN YANLEMO MARKET KANO STATE
}

\author{
*Lawan, I., Yahaya, K., Ahmad, Rabi K. and Muhammad, A. I. \\ Department of Agricultural and Environmental Engineering, Faculty of Engineering, Bayero University Kano \\ *Corresponding Author: ilawan.age@buk.edu.ng
}

\section{ABSTRACT}

Ergonomic evaluation of subjects involved in orange handling operation in Kano State was conducted. Anthropometric parameters were evaluated, where they were found to vary with age amongst the subjects selected. $20^{\text {th }}$ and $80^{\text {th }}$ percentiles of the dimensions were computed and recommended for usage in design of the relevant orange handling equipment. To evaluate the Physiological parameters, sorting/grading operations and washing operations were selected for this study. Results obtained revealed that, heart beat rate, oxygen consumption and energy expenditure varied amongst the subjects with age. Muscular stress and postural disorder were also studied. Comparing the parameters obtained during sorting/grading operation and that obtained during washing operations revealed that orange operations resulted to superior drudgery and musculoskeletal disorders.

Keywords: Anthropometrics, Energy expenditure, Drudgery, Operations and Musculoskeletal disorder

\section{INTRODUCTION}

Ergonomics focuses on human beings and their interaction with machines, materials, information, procedures and environments used in work and everyday living (Sanders and McCormick, 1992). Human factors discover and applied information about human behavior, capabilities, limitations, and other characteristics to the design of products, machines, systems, tasks, jobs, and work-environments for productive, safe, comfortable, and effective human use (Sanders and McCormick,1992). The International Labor Organization (ILO) has defined the term 'Ergonomics" as "the application of human biological sciences in conjunction with engineering sciences to the worker and his work environment, so as to obtain maximum job satisfaction, which at the same time enhances productivity" (Helander, 1995).

Ergonomics is the science of fitting the job to the worker. In a phrase, the task/job must 'fit the person' in all respects, and the work situation and environment should not compromise with human capabilities and limitations. In general, human factors find out the best possible match between the physical and mental demands of work and the capabilities of the individual members of the workforce in order to optimize both the productivity of the organization and the physiological cost of human beings. In a sense, the goal of human factors is to guide the applications of technology in the direction of benefiting humanity (Helander, 1995). Ergonomics has two major objectives. The first is to enhance the effectiveness and efficiency with which work and other activities are carried out, this includes such things as increased convenience of use, reduced errors and increased productivity. The second objective is to enhance certain desirable human values, including improved safety, reduced fatigue and stress, increased comfort, greater user acceptance, increased job satisfaction, and improved quality of life (Bridger, 1995). To develop the optimal conditions for the worker in work environment, to reduce physiological costs, to improve productivity, to facilitate instrument handling, to maximize the efficiency of operation and production system, and to minimize human errors ergonomics is essential (Bridger, 1995). Yanlemo market is a market specialized in fruit selling, and having orange as it major commodity, hence it is named Yanlemo (Badayi and Said, 2012). It is located at Naibawa area of Kumbotso Local Government area of Kano State, is part of the Market in the Metropolis of the State. Yanlemo Market is a third-generation market created in 1977. It is a regional Market as other trader from other neighboring States also patronize the Market.

Study conducted in this Market by Zahraddeen in 2015 revealed that orange handling operations (loading, unloading, transporting, sorting, grading, washing, packaging and storage) are characterized with drudgery as the operations are usually done manually and takes a lot of time to accomplish the task. However, his findings did not give details about the said drudgery in terms of energy expenditure, muscular stresses and postural discomfort. Thus, this study aimed at conducting ergonomic evaluation on the subjects involved in these handling operations so as to establish the actual status quo. The study therefore specifically aimed at; (i) determining the anthropometric parameters (height, arm length and weight) of subjects involved in orange handling operations in Yanlemo Market and (ii) determining the physiological parameters (blood pressure, heart beat, oxygen consumption, energy expenditure, muscular stress/postural discomfort) of the subjects involved in the handling operations in Yanlemo Market.

The findings of this study could provide detail information in terms of the anthropometrics of the people involved and the drudgery involved with the present methods used in carrying out the orange handling activities. 
Also, the information will be useful in design and fabrication of the related machines and as a basis for comparing the drudgery of the traditional methods and the machine to be developed.

\section{MATERIALS AND METHODS}

Materials Used in the Study

Materials used for this research work includes; (i) Weighing balance (OT58969 / Mesuca Tokyo Japan (ii) eighing balance (1304Bct/W\&T Avery Lmt Birmingham) (iii) Measuring tape (PJ / Pangi), (iv) Meter rule (PJ / Pangi), (v) Dual Head Stethoscope (DE0219/Frank Industries Inc, (vi) Digital Camera (Sony DSCW800/B) (vii) Stop Watch (Tecno W5 Lite)

\section{METHODS}

\section{Study Area}

Yanlemo Market which is located at Naibawa area of Kumbotso Local Government area of Kano State. The State is the second largest in terms of commercial activities in the Country. It has commerce as the second largest sector of its economy after Agriculture. The Yanlemo Market is part of the market in the Metropolis of the State. It is located at Naibawa Area of the Local Government, which is along Kano - Zaria Road, some kilometers from the city capital.

\section{Selection of Subjects}

A total of twenty-five (25) male subjects were selected at random five (5) from the following age group; 10-18, 19-27, 28-36, 37-45, 46-Above and from different locations of the Study Area.

\section{Determination of Anthropometric Parameters} of the Subjects

The anthropometric parameters evaluated includes; standing height, arm length and weight. Five (5) measurements from each age group were measured and documented.

\section{Determination of Physiological Parameters of the Subject}

Parameters evaluated were; blood pressure, heart beat, oxygen consumption, energy expenditure and muscular stress/postural discomfort. Stethoscope was used for measuring the heart beats. Each subject physiological parameter was measured and recorded before and after each sorting/grading and washing operation, as reported by Ademola (2015).

The oxygen consumption rate of the subjects was estimated using methods reported by Ademola (2015) with equation 2.1 .

$\mathrm{Y}=0.0114 \quad \times \quad \times \quad-\quad 0.68$

Where; $Y$ is the oxygen consumption (L/min), $X$ is the heart beat rate after handling operation (Beats/min).

Also, the energy expenditure was calculated using the formula given in (Equation 2);

$\mathrm{EE} \quad=\quad(0.159 \quad \times \quad H R) \quad-\quad 8.72$ (2)

Where; $E E$ is the energy expenditure $(\mathrm{kJ} / \mathrm{min})$ and $H R$ is the heart beat rate after handling operation (beats/min).

Assessment of postural discomfort included overall discomfort rating (ODR) and body part discomfort score (BPDS) was done as published by Corlett and Bishop (1976). After each of the operations, the subjects were asked to describe their body discomfort. For the assessment of ODR, a 5 - point psychophysical rating scale ( 1 - very mild, 5 - very severe) was used. The overall discomfort ratings given by each of the twenty-five (25) subjects was recorded. The template for severity and body regions and abbreviations were adopted from Corlett and Bishop (1976) as given in Table 1 and 2 respectively.

Table 1: Pain Severity Template

\begin{tabular}{cc}
$\begin{array}{c}\text { Severity of Pain After Handling Operation } \\
\text { Intensity of Pain }\end{array}$ \\
\hline 5 & Very Severe \\
4 & Severe \\
3 & Moderate \\
2 & Mild \\
1 & Very Mild \\
\hline
\end{tabular}

Table 2: Body Region and Abbreviations

\begin{tabular}{clc}
\hline S/N & \multicolumn{1}{c}{ BODY REGIONS } & AVBBREVIATIONS \\
\hline 1 & NECK & NK \\
2 & SHOULDER & SH \\
3 & UPPER BODY & UB \\
4 & LOWER BODY & LB \\
5 & UPPER ARM & UA \\
6 & LOWER ARM & LA \\
7 & ELBOW & EW \\
8 & WRIST & WT \\
9 & PALM/FINGER & PF \\
10 & THIGHS & TH \\
11 & KNEES & KN \\
12 & LEGS & LG \\
13 & ANKLE/FEET & AF \\
\hline
\end{tabular}


Bajopas Volume 10 Number 2 December, 2017

Analysis of the Result

Results obtained were analyzed using mean, range and percentiles.

\section{RESULTS AND DISCUSSION}

Anthropometrics Dimensions of the Subjects

The body weight of the subjects was observed to increase with age from age group $10-18$ to $37-45$, while there was a decline in body weight from age group 46 - above. Maximum body weight was observed from age group 37 - 45. The arm length increases with an increase in age while no definite pattern was noticed for the variation in height within the age group. Similar results were obtained by AvilaCarvalho et al., (2012), Mugisa et al., (2016) and Syuab (2015). The result of the anthropometric data for the subjects, and relationship of age on the anthropometric data of the subjects is presented in the Table 3.

Table 3: Anthropometric data for Subjects

\begin{tabular}{|c|c|c|c|c|c|}
\hline Age (yrs.) & Anthropometric Parameter & Range & Mean & $20^{\text {th }}$ percentile & $80^{\text {th }}$ percentile \\
\hline \multirow[t]{3}{*}{$10-18$} & Weight $(\mathrm{kg})$ & $45-59$ & 52 & 47 & 57 \\
\hline & Height $(\mathrm{cm})$ & $160-170$ & 166 & 162.5 & 169 \\
\hline & Arm Length (cm) & $58-65$ & 61.8 & 59.5 & 64 \\
\hline \multirow[t]{3}{*}{$19-27$} & Weight (kg) & $57-65$ & 61 & 58 & 64 \\
\hline & Height (cm) & $168-175$ & 170.8 & 168.5 & 174 \\
\hline & Arm Length (cm) & $65-71$ & 68.4 & 66 & 70.5 \\
\hline \multirow[t]{3}{*}{$28-36$} & Weight $(\mathrm{kg})$ & $667-75$ & 70.6 & 68 & 73.5 \\
\hline & Height (cm) & $165-179$ & 172 & 167 & 178.5 \\
\hline & Arm Length $(\mathrm{cm})$ & $65-72$ & 68.4 & 66 & 71 \\
\hline \multirow[t]{3}{*}{$37-45$} & Weight (kg) & $68-76$ & 72.6 & 70 & 75 \\
\hline & Height $(\mathrm{cm})$ & $171-176$ & 173.8 & 172 & 175.5 \\
\hline & Arm Length $(\mathrm{cm})$ & $65-73$ & 69.6 & 67 & 72 \\
\hline \multirow[t]{3}{*}{46 - Above } & Weight (kg) & $63-69$ & 65.8 & 63.5 & 68.5 \\
\hline & Height (cm) & $166-177$ & 172 & 167 & 176 \\
\hline & Arm Length $(\mathrm{cm})$ & $68-70$ & 69.4 & 68.5 & 70 \\
\hline
\end{tabular}

Physiological Evaluation of the Subjects

The result obtained for the physiological evaluation of the subjects Heart beat rate at normal rest position and after the sorting and grading operation is represented by Table 4 . While Figure 1 represent a chart showing the relationship between the increase in the average heart beat rate per minute of the subjects before and after sorting and grading operation in relationship to the subjects age group.
Average heart beat (Beats/min) and energy expenditure $(\mathrm{KJ} / \mathrm{min})$ were found to increase with increase in age of the respondents. Increase in average heart beat from 66.8 to 78 beats/min was recorded and increase in energy expenditure from 1.9012 to $3.6821 \mathrm{KJ} / \mathrm{min}$ was also recorded for the different age groups considered in this study. Similar trend of variation of heart beat rate with age for workers was reported by Tycho et al., (2007).

Table 4: Physiological Evaluation of the Subjects during Sorting and Grading Operation

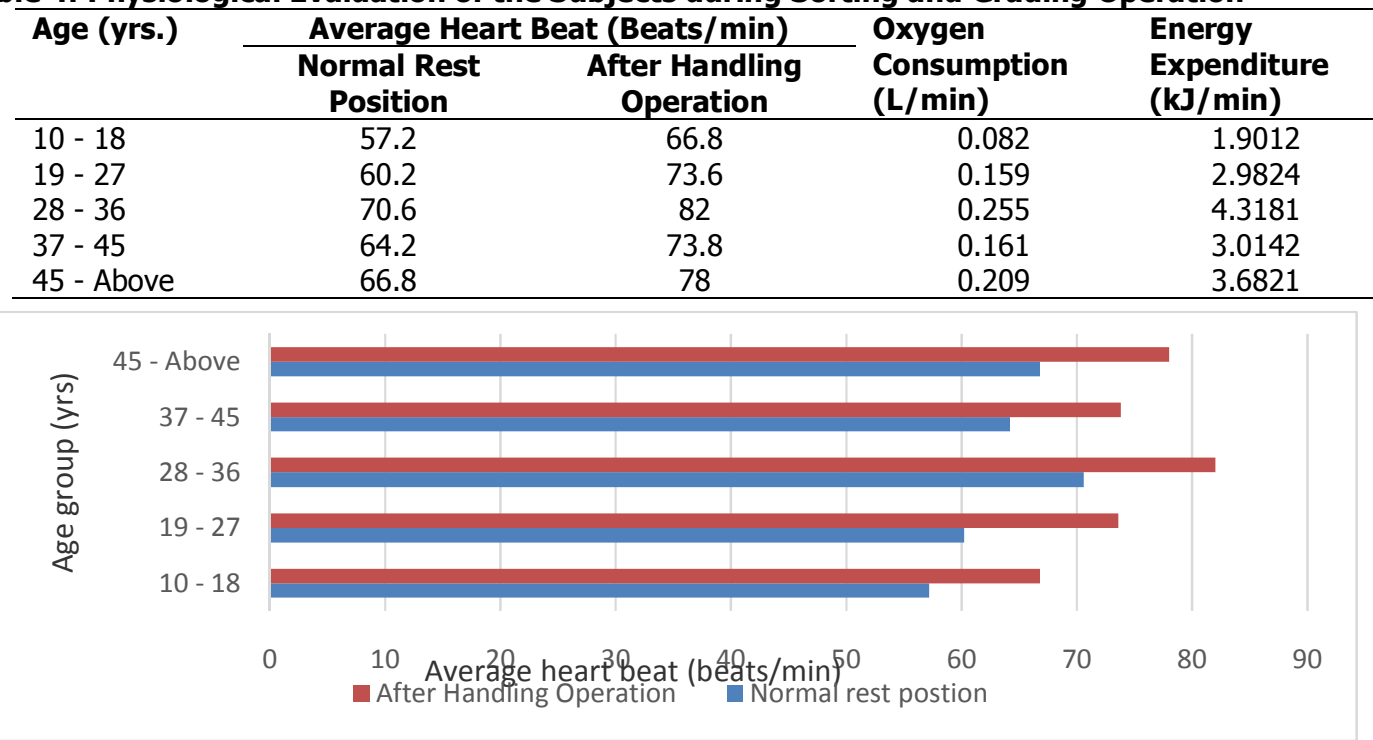

Figure 1: Chart of Average Heart Beat per Minute of the Subjects against Age Group during Sorting and Grading Operation 
Also from the result obtained, it is observed that there was more difference in the heart beat rate from the age group of $28-36$ and above compare to $19-27$ and below after the operation. The result obtained for the physiological evaluation of the subject's heart beat rate at normal rest position and after the washing operation is shown in Table 5 . While figure 2 represent a chart showing the relationship between the increase in the average heart beat rate per minute of the subjects before and after handling operation in relationship to the subjects age group. Also from the result obtained, it is observed that there was more difference in the heart beat rate from the age group of 28 - 36 and above when compared to $19-27$ and below after the operation. This trend has also been established by Tycho et al., (2007).

Table 5: Physiological Evaluation of the Subjects during Washing Operation

\begin{tabular}{lcccc}
\hline Age (yrs.) & Average Heart Beat (Beats/min) & $\begin{array}{l}\text { Oxygen } \\
\text { Consumption } \\
\text { (L/min) }\end{array}$ & $\begin{array}{l}\text { Energy } \\
\text { Expenditure } \\
\text { (kJ/min) }\end{array}$ \\
\cline { 2 - 3 } & $\begin{array}{c}\text { Normal Rest } \\
\text { Position }\end{array}$ & $\begin{array}{c}\text { After Handling } \\
\text { Operation }\end{array}$ & \\
\hline $10-18$ & 57.2 & 73.2 & 0.156 & 2.9188 \\
$19-27$ & 60.2 & 73.2 & 0.156 & 2.9188 \\
$28-36$ & 70.6 & 83.8 & 0.275 & 4.6042 \\
$37-45$ & 64.2 & 78.4 & 0.214 & 3.7456 \\
$45-$ Above & 66.8 & 83 & 0.266 & 4.4770 \\
\hline
\end{tabular}

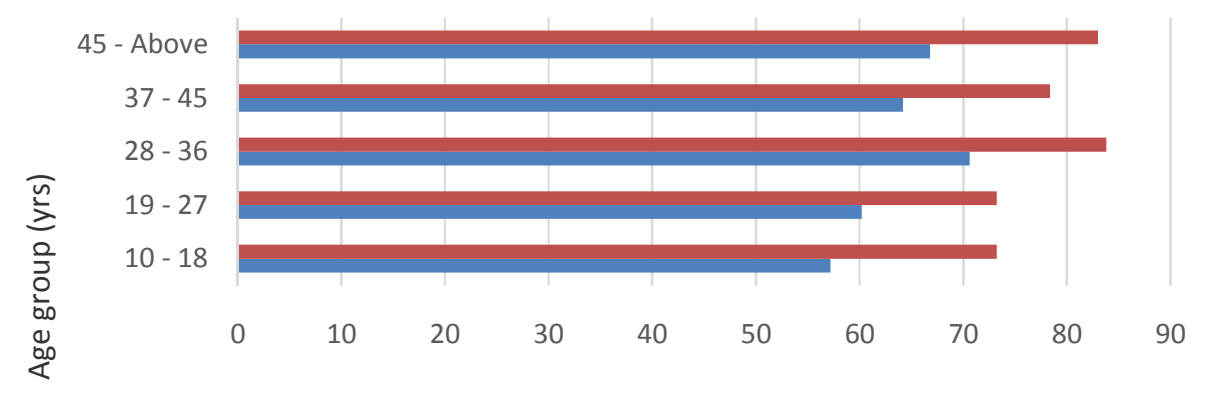

Average heart beat (beats/min)

after Handling Operation Normal rest position

Figure 2: Chart of Average Heart Beat per Minute of the Subjects against Age Group during Washing Operation

From the analysis, the results have shown that more energy is been expended during the washing operation compared to the sorting/grading operation. It has also revealed that more energy expenditure occurs between the age group of $10-18$ and $45-$

above. Figure 3 represent a chart showing this analysis. Similar trend of variation of energy expenditure with age for workers was reported by Tycho et al., (2007).

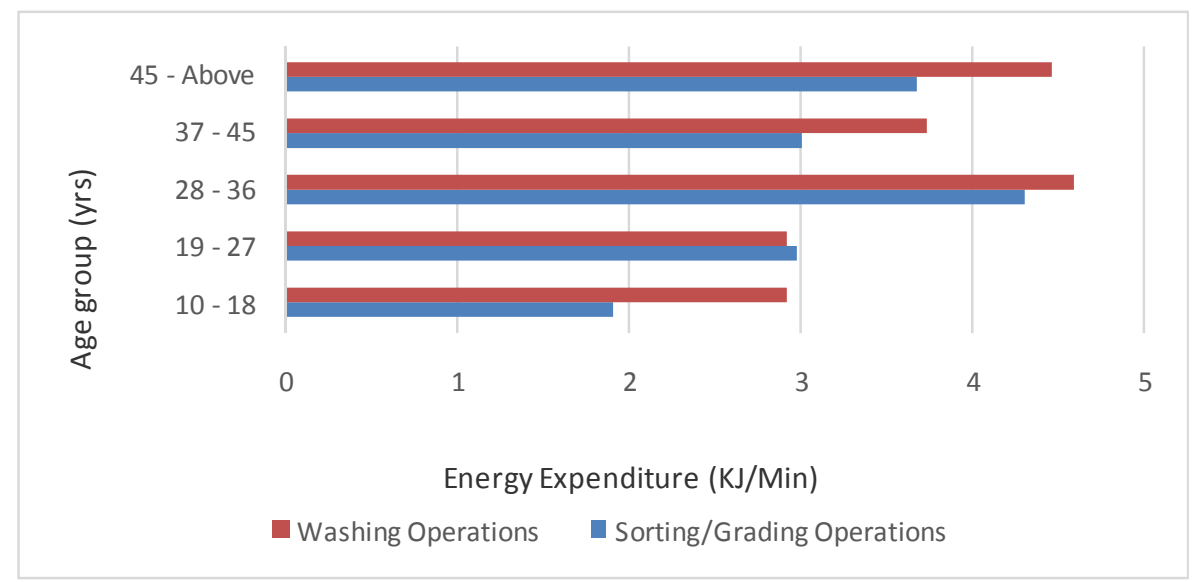

Figure 3: Chart of Comparison of Energy Expenditure Between Washing and Sorting/Grading 


\section{Operation Against Age Group}

For the Assessment of body parts discomfort of the subjects during the operations, result obtained revealed that, 23 out of 25 subjects which represents $92 \%$ complained of lower back pain after the during the sorting and grading operation, followed by 19 out of 25 subjects which represent $76 \%$ complained of neck pain and upper arm pain. These could be attributed to the poor posture experienced during the operation. Similar findings were published by Saemee and Karen (2016). Figure 4 shows data for muscular and postural discomfort for sorting/grading operation.

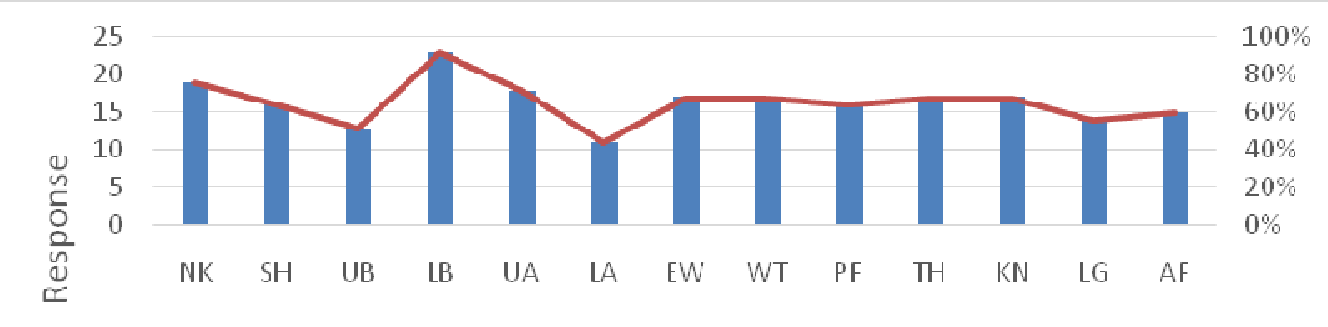

Respongly Parts ercentage

Figure 4: Chart Representing Muscular and Postural Discomfort for Sorting/Grading

From the result obtained, 23 out of 25 subjects which represents $92 \%$ complained of lower back pain after the operation, followed by 21 out of 25 subjects which represent $84 \%$ complained of upper arm pain, while 19 out of the 25 subjects which represent $76 \%$ complain of Palm/Finger pain. These could be attributed to the poor posture experienced during the operation. Similar findings were published by Saemee and Karen (2016). Figure 5 shows data for muscular and postural discomfort for sorting/grading operation.

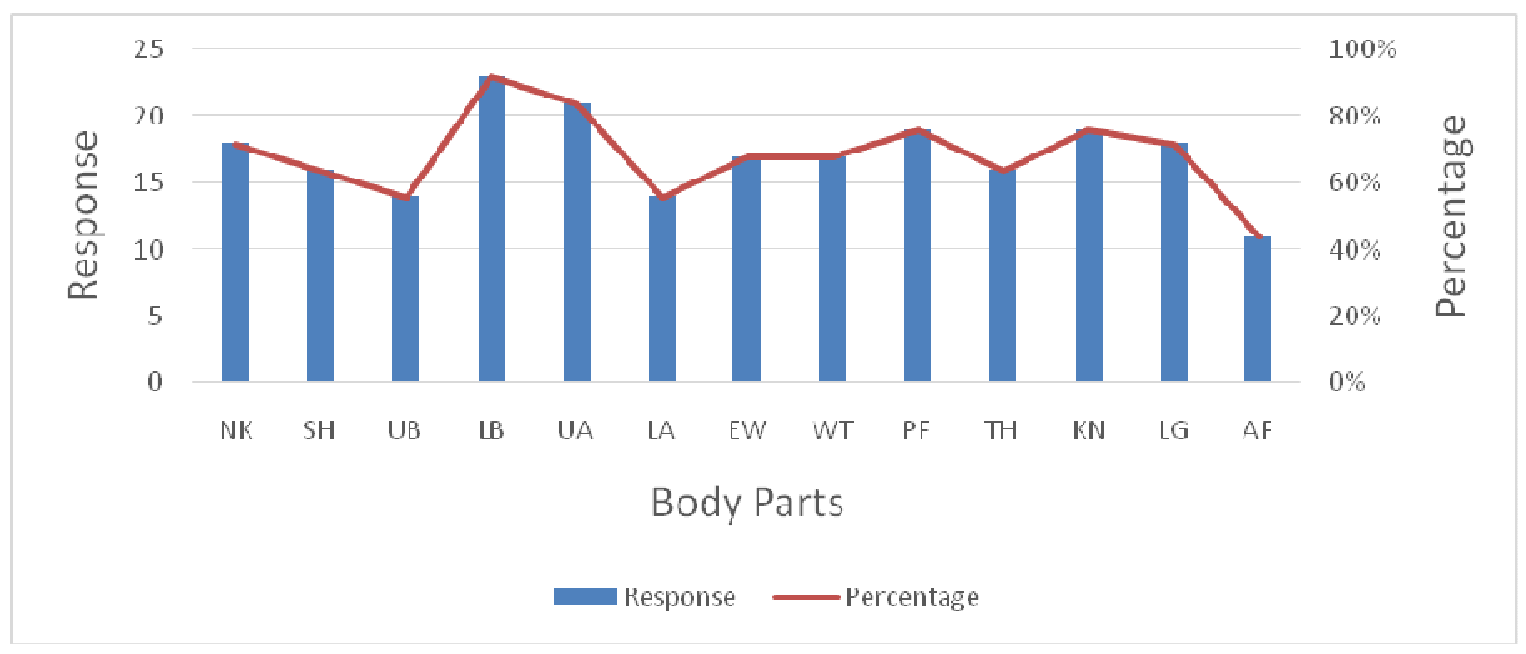

Figure 5: Chart Representing Muscular and Postural Discomfort for Washing

\section{CONCLUSIONS AND RECOMMENDATION}

The ergonomic evaluation of subjects involved in orange handling operation was conducted and the following conclusions were drawn;

i. All the anthropometric parameters of the subjects recorded were found to increase with age.

ii. The heartbeat rate, oxygen consumption and energy expenditure of the subjects were also found to increase with increase in age of the subjects. Especially the heart rate.

iii. Almost all the subjects involved in the orange handling operations complained of pains in various parts of their body, lower back pain was recorded to be the commonest amongst the subjects.

$$
\text { Therefore, the following }
$$
recommendations were raised;

i. While designing any orange handling equipment/ machine, $20^{\text {th }}$ percentile values obtained should be used for design where the lower limit is the restrictive factor and $80^{\text {th }}$ percentile for design where the upper limit is the restrictive factor, with respect to the targeted age groups must be considered for efficiency and comport. 
Bajopas Volume 10 Number 2 December, 2017

ii. Appropriate power source must be use while designing any orange handling equipment/machine especially for higher age groups for comfortability, safety, suitability and reduced the drudgery.

iii. Appropriate posture should be considered while developing any orange handling equipment/machine. To prevent body pains as a

\section{REFERENCES}

Ademola K, (2015): Ergonomics Evaluation of a Manually Operated Multi-Purpose Juice Extractor 1(1): 27-32

Avila-Carvalho, Klentrou, P., Palomero da Luz., M., and Lebre, E. (2012): Anthropometric Profiles at Menarche in Elite Group Rhythmic Gymnasts According to their Chronological Age. Journal of Science and Sports, 28, 172180.

Badayi and Said (2012): Structure of Kano Economic, Paper published on www.kanoonline.com

Bridger, R.S. (1995): International editions, Introduction to Ergonomics, McGraw-Hill, Inc.

Corlett, E.N. and.Bishop R.P. (1976): A Technique for Assessing Postural Discomfort. Ergonomics, 19:175- 182

Helander and Martin, (1995): East-West Press edition, A Guide to the Ergonomics of Manufacturing, pp. 1-6

Mugisa, D. L., Katimbo, A., Sempiira, J. E., Kisaalita, W. S. (2016): Anthropometric Characteristics of Female Small Holder Farmers of Uganda- result of musculoskeletal disorders that results from poor working posture.

Contribution of Authors: All the authors involved in this paper have contributed to the success of this study.

Conflict of Interest: The authors declare that there is no conflict of interest

Towards Design of Labour Saving Tools. Journal of Applied Ergonomics, 54, 177-185.

Sander Mark S. and McCormick Ernest J, (1992): Human Factors in Engineering and Design, 7th edition McGraw-Hill, Inc.

Saemee, L.and Karen, L.L (2016): Effects of Natural Posture Imbalance on Posture Deviation Caused by Load Carriage. International Journal of Industrial Ergonomics, 56, 115123.

Syuab, M. F. (2015): Anthropometric Study of Farm Workers on Java Island, Indonesia and its Implications for the Design of Farm Tools and Equipments. Journal of Applied Ergonomics, 51, 222-235.

Tycho, K.F., Anil, R.K., Sadat, K. (2007): $A n$ Ergonomic Evaluation of Metal Pouring Operation. International Journal of Industrial Ergonomics 38(2008) 182-192.

Zaharaddeen U. (2015): Study on the handling system of an Orange (Case Study of Kano State). Unpublished B.Eng. research, Agricultural and Environmental Engineering Department, Bayero University, Kano. 